\title{
Mesohabitat mosaic in lowland braided rivers: Short-term variability of macroinvertebrate metacommunities
}

\author{
Gemma BURGAZZI, ${ }^{*}$ Alex LAINI, Erica RACCHETTI, Pierluigi VIAROLI \\ Department of Chemistry, Life Sciences and Environmental Sustainability, University of Parma, Viale G.P. Usberti 33/A, 43124 \\ Parma, Italy \\ *Corresponding author: gemma.burgazzi@unipr.it
}

\begin{abstract}
Braided rivers are among the most variable and dynamic riverine systems. Changes in these environments are sudden and frequent, driven by the high hydrological variability. They host high levels of local heterogeneity, with many different habitats in close proximity establishing a mosaic of patches. This provides the conditions for high levels of biodiversity, with strong community variability in particular among the different habitats at the stream-reach level. Nevertheless, these systems are still poorly studied and their complexity is often not taken into account in biomonitoring protocols. We applied mixed effects modelling, spatial ordination techniques and beta-diversity partitioning (into nestedness and turnover components) with the aim of improving the knowledge of braided rivers, investigating: i) the organization of macroinvertebrate communities among the different habitats of a river reach, and ii) the temporal variability of this organization (both among seasons and during summer). We predicted a differentiation of macroinvertebrate communities between distinct habitats within rivers, with this differentiation increasing during the low-flow period. We carried out our study in four braided rivers and streams of the Po River basin (Northern Italy) sampling three different kinds of mesohabitats (main channel, secondary channel and pool) in eight stations during seven campaigns from June 2015 to April 2016. We found a high variability of taxa richness, abundance and community structure among mesohabitats, with marginal ones accounting for the greater part of macroinvertebrate diversity. Secondary channels resulted as being the habitat hosting greater taxa diversity, with 10 exclusive taxa. Surprisingly the mesohabitat communities differed greatly during the seasonal phase, whereas their dissimilarity decreased during summer. This could be explained considering the summer flow reduction as a homogenizing force, leading to a general loss of the most sensitive taxa. However, the summer taxa turnover value resulted higher than nestedness, suggesting a strong environmental control on community organization, with taxa well adapted to the different conditions of mesohabitats and able to manage the effects of flow reduction. Our work represents a remarkable issue for biomonitoring protocols, highlighting the importance of taking into account the whole complexity of braided rivers for a more realistic evaluation of macroinvertebrate communities.
\end{abstract}

Key word: Braided rivers; macroinvertebrate metacommunity; mesohabitat; short-term variability; macroinvertebrate distribution.

\section{INTRODUCTION}

Braided rivers (BRs) are defined as "systems composed by multiple channels, with bars and islands, often with poorly defined banks of non-cohesive sedimentary materials" (Tockner et al., 2006). These systems are spread worldwide and can be found in delta areas, where rivers enter lakes and oceans, or in floodplains in presence of low slope and sandy or gravel-filled substrates (Dodds, 2002). The main feature that shapes BRs is the extreme flow variability. The alternation of sudden and frequent flow changes, spanning flash floods and dry periods generates a mosaic of patches (embracing different degrees of lotic and lentic conditions), which undergoes rapid evolution (Gray and Harding, 2009). Events like the displacement of channels or disconnection of habitats can happen within short periods, spanning from a few weeks to a few hours. Van der Nat et al. (2003) estimated the turnover time of the different habitats in a BR system (Tagliamento, NE
Italy) reporting a high level of variation, with a total replacement of all the aquatic habitats of $82 \%$ during the period of study (2.5 years). Nevertheless, they reported that the relative proportion of the various habitats remained quite consistent. Based on these results, BRs can be conformed to the "shifting mosaic steady model" that identify systems where the habitat turnover is high but the proportions of habitats are constant (Tockner et al., 2006; Gray and Harding, 2011).

Based on these attributes, BRs can be considered as very suitable systems for studying metacommunity dynamics. According to the metacommunity theory (Leibold et al., 2004), environmental heterogeneity and taxa features (e.g., dispersal ability and competition) determine the structure and evolution of metacommunities at different spatial scales (Siqueira et al., 2012; McLaughlin et al., 2013). In general, habitat heterogeneity has a positive effect on species richness (Poff and Ward, 1990; Garcia et al., 2012; Astorga et al., 2014), enhancing the niche availability and allowing the co-occurrence of taxa with dif- 
ferent requirements. The high dynamism of BRs generates a great heterogeneity, especially at the scale of river reach, with a wide range of different habitats, spanning from lotic to lentic conditions and with a time-variable level of connection. The degree of influence of dispersal dynamics and environmental forcing is strictly related to the connectivity of habitats, besides the dispersal ability of taxa (Padial et al., 2014). In riverine systems, the level of connectivity can change widely in time and among them BRs are one of the most dynamic and complex (Ward et al., 2002). All these conditions are the basis for the presence of biodiversity hot-spots, with high levels of diversity variation in particular among the different habitats at the stream-reach level. In fact, several authors pointed out high levels of lateral variation in taxa diversity and community structure for braided systems (e.g., Arscott et al., 2005; Gray and Harding, 2007, respectively in north-eastern Italy and New Zealand). Similar outputs were also recorded for primary producers in lowland rivers largely fed by groundwater (Bolpagni and Laini, 2016), suggesting the existence of complex metabolic gradients across habitats in hydro-systems.

The variation among habitats can be considered as a beta-diversity variation and therefore it can be ascribed to two different phenomena: nestedness and spatial turnover. Nestedness occurs when there is a non-random taxa loss, with the result that the poorer communities are a subset of the richer ones, while turnover is the result of taxa replacement (Baselga, 2010). Datry et al. (2016) highlighted that turnover is more related to environmental filtering, while nestedness is given by dispersal limitation. These two processes can assume differential importance in shaping local communities, in particular during low-flow periods, when connectivity among habitats is more variable.

Although these systems are widespread and considered as diversity hot-spots, for years they have been poorly studied (Gray and Harding, 2007), with a lack of knowledge, especially in how the different habitats in the river segment contribute to the total diversity and how these patterns change in time. This topic is particularly relevant considering that BRs are often located in areas heavily impacted by human activities, with all the possible consequences, like considerable water withdrawals, canalization and reduction or loss of lateral areas (Tockner et al., 2006; Gray and Harding 2011; Karaus et al., 2013). These phenomena lead to a trivialization of BRs, with the consequent reduction of habitat variability. Therefore, a good understanding of habitat heterogeneity contribution to the local diversity becomes a key point for biodiversity conservation.

The aims of this study are therefore i) to evaluate the seasonal structure and variation of benthic macroinvertebrate communities within the highly patchy environments of BRs and ii) to evaluate the short-term variability of these communities during the low-flow period. For this work, we focused on the mesohabitat sampling unit, demarcated according to the hydrodynamic characteristics in main channel, secondary channel and pool. Tickner et al. (2000) defined mesohabitats as "medium-scale habitats which arise through the interactions of hydrological and geomorphological forces". We hypothesize that: i) in general there is a differentiation of macroinvertebrate communities between different mesohabitats within rivers, and between considered seasons ii) during lowflow periods, with the increasing disconnection of mesohabitats there is an increase in community dissimilarity, with higher turnover in the less disconnected mesohabitats and higher nestedness in the more disconnected ones.

\section{METHODS}

\section{Study area}

The study was performed in four braided watercourses (Trebbia River, Nure Stream, Taro River and Baganza Stream) of the Po River basin (Northern Italy, Fig. 1A). A description of the studied systems is reported in Tab.1. They are fed only by wet depositions and they present two high discharge periods (in autumn and spring) and a main low water period in summer (with a secondary additional one in winter). They are included in the Cfa (humid subtropical climate) and Csa (hot-summer Mediterranean climate) climatic regions. For each watercourse we selected two sampling stations in order to take into account the within river variability. Within each station, three model mesohabitats were further selected: main channel, secondary channel, and pool (Fig. 1B). For the first part of the study (seasonal phase, T6-T7) sampling was carried out in November 2015 and in April 2016 in the whole set of systems. For the second part (summer phase, T1-T5) the set of investigated systems was reduced to two (Trebbia and Taro rivers) and the sampling was carried out in five occasions in the period of low flow, from June to September 2015. The downsizing of sampled area was operated because i) Nure and Baganza streams completely dried up during the summer season and ii) to contain the sampling and processing effort.

\section{Physical and chemical variables}

In order to check the difference between mesohabitats, for each sampling environmental data were collected with five random replicates (Fig. 1B). Flow velocity, water depth, temperature, conductivity and dissolved oxygen were recorded in situ by means of a current meter (FP101FP102 Global Flow Probe) and a multi-parametric probe (HI 9828; Hanna Instruments). Water samples were collected for the determination of ammonium $\left(\mathrm{NH}_{4}^{+}\right)$, nitrite $\left(\mathrm{NO}_{2}^{-}\right)$, nitrate $\left(\mathrm{NO}_{3}^{-}\right)$, soluble reactive phosphorous (SRP), dissolved silica $\left(\mathrm{SiO}_{2}\right)$ and total dissolved inorganic 
carbon $\left(\mathrm{TCO}_{2}\right)$. Detection limits were $0.01 \mathrm{mg} \mathrm{L}^{-1}$ for $\mathrm{NH}_{4}^{+}, \mathrm{NO}_{3}^{-}$, SRP and $\mathrm{SiO}_{2}, 0.005 \mathrm{mg} \mathrm{L}^{-1}$ for $\mathrm{NO}_{2}^{-}$, and $0.02 \mathrm{mM}$ for $\mathrm{TCO}_{2}$. Precision ranged between $\pm 3 \%$ and $\pm 5 \%$. Chemical analyses were performed by means of spectrophotometric techniques, according to Valderrama (1977), Golterman et al. (1978), and APHA (2012).
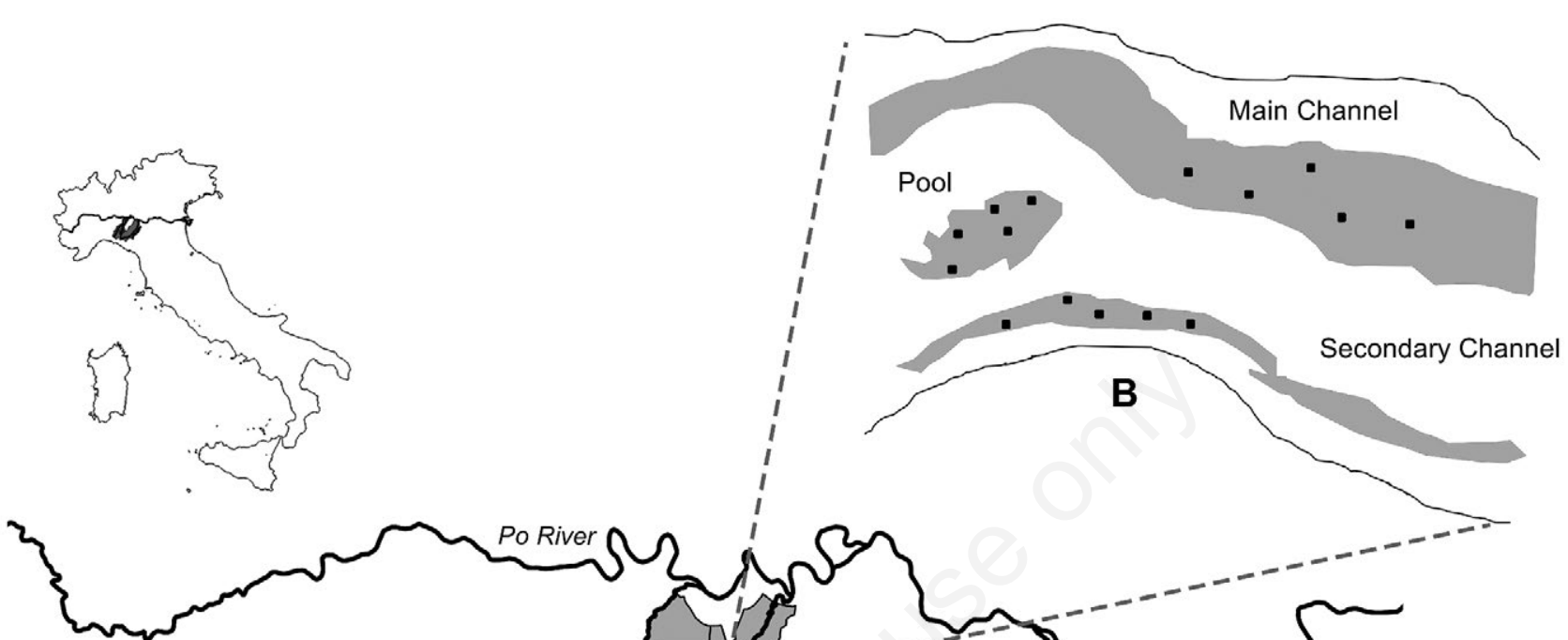

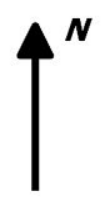

$\begin{array}{lllll}0 & 10 & 20 & 30 & 40\end{array}$

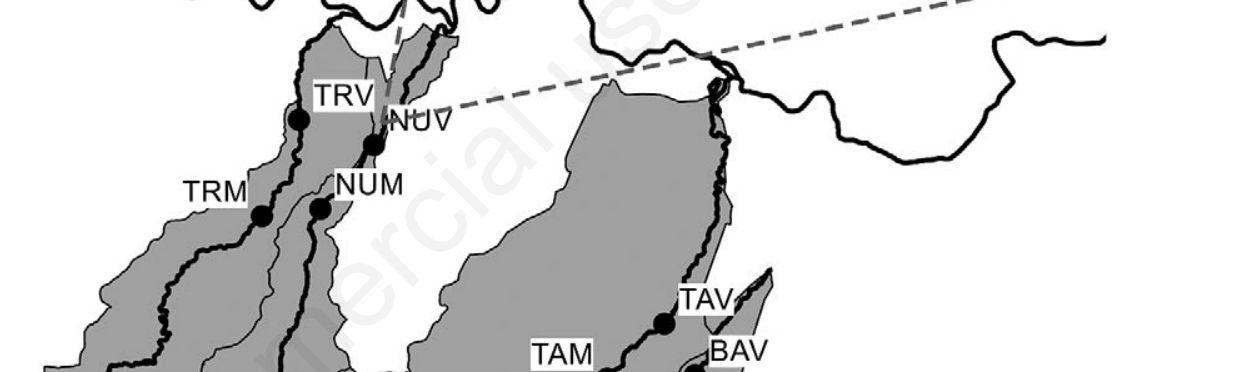

Fig. 1. Map of the sampled area (A), with the studied basins coloured in grey and the sampling stations marked with black dots, and the sampling design (B) repeated in each of the sampling stations. Black squares represent the random sampling plots.

Tab. 1. Descriptive data of the investigated rivers/streams and stations.

\begin{tabular}{|c|c|c|c|c|c|c|c|c|c|}
\hline River/stream & $\begin{array}{c}\text { Qm } \\
\left(\mathrm{m}^{3} \mathrm{~s}^{-1}\right)\end{array}$ & $\begin{array}{c}\mathrm{L} \\
(\mathrm{km})\end{array}$ & $\begin{array}{c}\mathrm{A} \\
\left(\mathrm{km}^{2}\right)\end{array}$ & Station & Latitude & Longitude & $\begin{array}{c}\text { Altitude } \\
\text { (m asl) }\end{array}$ & $\begin{array}{l}\text { W } \\
(\mathrm{m})\end{array}$ & $\begin{array}{c}\text { D } \\
(\mathrm{km})\end{array}$ \\
\hline Trebbia & 22.0 & 120 & 1083 & $\begin{array}{l}\text { TRM } \\
\text { TRV }\end{array}$ & $\begin{array}{l}44^{\circ} 51^{\prime} 11.05^{\prime \prime} \mathrm{N} \\
44^{\circ} 58^{\prime} 18.51^{\prime \prime} \mathrm{N}\end{array}$ & $\begin{array}{l}9^{\circ} 32^{\prime} 11.75^{\prime \prime} \mathrm{E} \\
9^{\circ} 35^{\prime} 32.54^{\prime \prime} \mathrm{E}\end{array}$ & $\begin{array}{c}166 \\
97\end{array}$ & $\begin{array}{l}298 \\
440\end{array}$ & 13.9 \\
\hline Nure & 15.0 & 77 & 458 & $\begin{array}{l}\text { NUM } \\
\text { NUV }\end{array}$ & $\begin{array}{l}44^{\circ} 51^{\prime} 52.84^{\prime \prime} \mathrm{N} \\
44^{\circ} 55^{\prime} 55.97^{\prime} \mathrm{N}\end{array}$ & $\begin{array}{l}9^{\circ} 37^{\prime} 48.73 \text { '” } \\
9^{\circ} 42^{\prime} 40.966^{\prime \prime} \mathrm{E}\end{array}$ & $\begin{array}{l}212 \\
124\end{array}$ & $\begin{array}{l}240 \\
244\end{array}$ & 9.9 \\
\hline Taro & 40.5 & 138 & 2051 & $\begin{array}{l}\text { TAM } \\
\text { TAV }\end{array}$ & $\begin{array}{l}44^{\circ} 40^{\prime} 27.92^{\prime \prime} \mathrm{N} \\
44^{\circ} 44^{\prime} 26.97^{\prime \prime} \mathrm{N}\end{array}$ & $\begin{array}{l}10^{\circ} 4{ }^{\prime} 23.03 \text { ' } \mathrm{E} \\
10^{\circ} 10^{\prime} 6.14^{\prime \prime} \mathrm{E}\end{array}$ & $\begin{array}{c}151 \\
95\end{array}$ & $\begin{array}{l}530 \\
445\end{array}$ & 10.6 \\
\hline Baganza & 5.2 & 59 & 228 & $\begin{array}{l}\text { BAM } \\
\text { BAV }\end{array}$ & $\begin{array}{l}44^{\circ} 37^{\prime} 54.67^{\prime} \mathrm{N} \\
44^{\circ} 40^{\prime} 54.20^{\prime} \mathrm{N}\end{array}$ & $\begin{array}{l}10^{\circ} 10^{\prime} 10.33^{\prime \prime} \mathrm{E} \\
10^{\circ} 12^{\prime} 36.90^{\prime \prime} \mathrm{E}\end{array}$ & $\begin{array}{l}308 \\
213\end{array}$ & $\begin{array}{l}106 \\
183\end{array}$ & 6.4 \\
\hline
\end{tabular}

Qm, mean annual flow; $L$, total length; $A$, basin area; $W$, width of the riverbed; $D$, linear distance between stations. 


\section{Macroinvertebrates}

In each mesohabitat, a $\sim 50 \mathrm{~m}$ long stretch was sampled, choosing five random sampling points (Fig. 1B). Samples were collected using a surber net with frame area of $0.1 \mathrm{~m}^{2}$ and mesh size of $500 \mu \mathrm{m}$. The five replicates were cumulated for each mesohabitat. Samples were filtered and preserved in 70\% ethanol for laboratory sorting, where the organisms were counted and identified to family or genus level, according to Tachet et al. (2010).

\section{Data analysis}

The difference between mesohabitats, in terms of physical variables, was assessed by means of mixed effects modelling, considering mesohabitat and time (sampling date) as fixed effects and station and site (namely the specific sampling location) as hierarchically organized random effects. A similar approach was followed also for testing the influence of mesohabitat and time on richness and abundance. The significance was checked by means of a likelihood-ratio test. The use of these models allows us to work with correlated and non-normally distributed data (McCulloch and Neuhaus, 2005), typical of nested and hierarchical designs. The effect of covariate was tested both for seasonal and summer data. Then the distribution of taxa between mesohabitats at station level was checked, by estimating the mesohabitat contribution to the total number of taxa. We did this by computing the percentage ratio for each station between the richness of each mesohabitat and the total richness of the station.

The organization of community structure in mesohabitats was explored with a non-Metric Multidimensional Scaling (nMDS), a spatial ordination technique that represents the set of objects along a predetermined number of axes maintaining the ordering relationships among them (Borcard et al., 2011). As dissimilarity measure Bray-Curtis distance was used and the goodness of ordination was assessed with the stress measure.

To assess the nature of diversity variation between mesohabitats during the summer phase we performed a partition of beta-diversity, following Baselga (2010). This method produces three metrics: the total beta-diversity (the Sørensen Dissimilarity index), for all the possible pairwise comparisons, and its two additive components: nestedness, expressing the taxa loss between mesohabitats, and the turnover, expressing the taxa substitution. The values of nestedness and turnover were normalized by dividing them by the Sørensen dissimilarity value. We checked the effect of time for the Sørensen Dissimilarity index by means of linear mixed effect models and then we adjusted the p-values using the Bonferroni correction for multiple comparisons. We also applied mixed effects modelling to check the difference between beta-diversity components and their variation in time.
All analyses and graphs were performed with the statistical software R (R Core Team, 2016), with base version and with ggplot2 (Wickham, 2009), lme4 (Bates et al., 2015), vegan (Oksanen et al., 2016) and betapart (Baselga et al., 2013) packages.

\section{RESULTS}

\section{Physical and chemical variables}

Mean values of measured physical and chemical variables are reported in Tab. 2, according to season and mesohabitat. The distinction between mesohabitats was tested for physical variables considering the whole dataset (seasonal and summer data) and we found that they differ greatly for flow velocity $(\mathrm{P}<0.001)$ and water depth $(\mathrm{P}<0.001)$, while the others variables (temperature, conductivity and percentage of dissolved oxygen) varied significantly only in time $(\mathrm{P}<0.001)$ but not between mesohabitats.

\section{Macroinvertebrates}

A total of 74122 organisms, belonging to 94 taxa (75 families) was found globally. The sample with the highest taxa richness (34 taxa) was collected at the beginning of the summer period in the upstream pool of Trebbia River, while the one with the lowest (seven taxa) in the downstream pool of Nure Stream, during the November sampling campaign. The mean values of taxa richness and abundance were $18 \pm 5$ and $837 \pm 743$ for main channels, $22 \pm 5$ and $796 \pm 546$ for secondary channels and $17 \pm 6$ and $426 \pm 552$ for pools. The list of most abundant (A) and frequent (B) taxa is reported in Fig. 2. Chironomidae was both the most abundant and frequent taxon (abundance $=$ $29.3 \%$, frequency $=99.1 \%$ ). Detection probabilities for the other most common taxa were unrelated to their abundance. Some taxa were found to be exclusive of one kind of mesohabitat: we found five exclusive taxa in the main channels (Heptagenia, Notonecta, Gordiidae, Besdolus and Brachyptera), six in the pools (Pseudocentroptilum, Pisidium, Dixidae, Hydrometra, Haplotaxidae and Protonemura) and 10 in the secondary channels (Hydridae, Blephariceridae, Dolichopodidae, Ephydridae, Rhagionidae, Valvata, Gerris, Helobdella, Nemoura and Lepidostomatidae).

The significance of mesohabitat and time for taxa richness and organism abundance was tested by means of several mixed effects models for seasonal and summer phases. Both taxa richness and abundance resulted related with mesohabitats, especially for seasonal data (P values 0.002 and 0.003 respectively), while for summer data these relations resulted weaker $(\mathrm{P}$ values 0.078 and 0.060 ). Time resulted significant only for the seasonal taxa richness $(\mathrm{P}=0.026)$, with a variation between No- 
vember and April, while no significant variation was found during summer nor for abundance. The effect of mesohabitat resulted clear also considering community composition patterns (Fig. 3 A,B): points corresponding to the three kinds of mesohabitats group into different areas of the nMDS plot, both for seasonal and summer
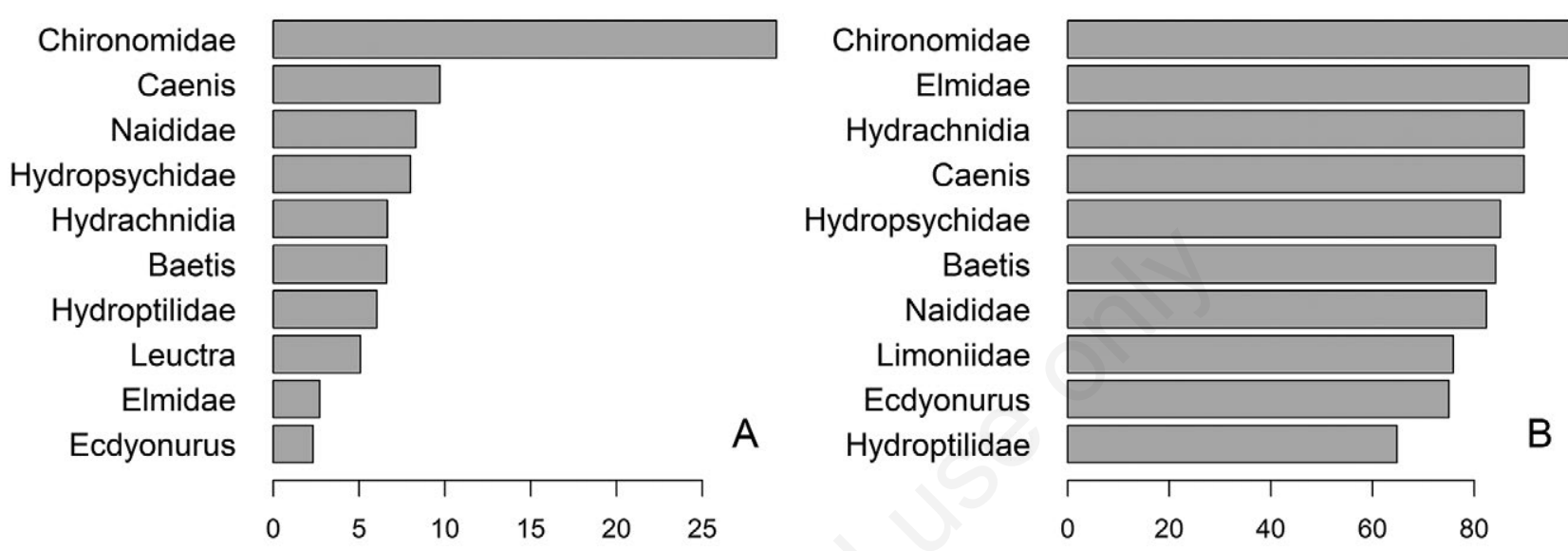

Fig. 2. Barplots of the first 10 taxa in terms of abundance percentage (A) and frequency percentage (B). Values are referred to the whole dataset.

Tab. 2. Physical and chemical variables for mesohabitats in each season. $\mathrm{NH}_{4}^{+}, \mathrm{NO}_{2}^{-}$and $\mathrm{SRP}$ values are not shown because always lower than detection values. Autumn and Spring values are for the whole set of systems, whereas Summer values are referred only to Trebbia and Taro rivers.

\begin{tabular}{|c|c|c|c|c|c|c|c|}
\hline & & \multicolumn{2}{|c|}{ Autumn } & \multicolumn{2}{|l|}{ Spring } & \multicolumn{2}{|c|}{ Summer } \\
\hline & & Mean values & SD & Mean values & SD & Mean values & SD \\
\hline \multirow[t]{3}{*}{ Flow velocity $\left(\mathrm{m} \mathrm{s}^{-1}\right)$} & Main & 0.47 & 0.24 & 0.46 & 0.07 & 0.42 & 0.16 \\
\hline & $\mathrm{Sec}$ & 0.31 & 0.36 & 0.14 & 0.07 & 0.22 & 0.19 \\
\hline & Pool & 0.08 & 0.15 & 0.00 & 0.01 & 0.07 & 0.13 \\
\hline \multirow[t]{3}{*}{ Water depth (cm) } & Main & 22.6 & 7.7 & 28.3 & 6.4 & 21.3 & 6.9 \\
\hline & $\mathrm{Sec}$ & 13.5 & 10.0 & 10.7 & 8.7 & 14.3 & 8.0 \\
\hline & Pool & 24.3 & 9.3 & 13.1 & 7.6 & 19.1 & 6.8 \\
\hline \multirow[t]{3}{*}{ Temperature $\left({ }^{\circ} \mathrm{C}\right)$} & Main & 13.0 & 1.2 & 14.1 & 1.3 & 23.5 & 2.0 \\
\hline & $\mathrm{Sec}$ & 13.8 & 1.5 & 14.9 & 2.2 & 23.7 & 3.8 \\
\hline & Pool & 13.3 & 1.3 & 15.4 & 1.6 & 24.6 & 1.9 \\
\hline \multirow[t]{3}{*}{ Conductivity $\left(\mu \mathrm{S} \mathrm{cm}^{-1}\right)$} & Main & 250 & 29 & 253 & 24 & 328 & 45 \\
\hline & Sec & 287 & 81 & 272 & 35 & 383 & 143 \\
\hline & Pool & 268 & 38 & 274 & 27 & 375 & 74 \\
\hline \multirow[t]{3}{*}{ Dissolved oxygen (\%) } & Main & 104.1 & 5.8 & 103.8 & 12.2 & 107.5 & 8.1 \\
\hline & $\mathrm{Sec}$ & 100.5 & 12.1 & 102.0 & 11.2 & 96.3 & 18.8 \\
\hline & Pool & 94.0 & 11.3 & 88.3 & 12.6 & 105.1 & 18.4 \\
\hline \multirow[t]{3}{*}{$\mathrm{NO}_{3}^{-}$} & Main & 0.29 & 0.08 & 0.16 & 0.08 & 0.23 & 0.14 \\
\hline & Sec & 0.36 & 0.22 & 0.17 & 0.09 & 0.49 & 0.64 \\
\hline & Pool & 0.31 & 0.07 & 0.21 & 0.06 & 0.44 & 0.67 \\
\hline \multirow[t]{3}{*}{$\mathrm{SiO}_{2}\left(\mathrm{mg} \mathrm{L}^{-1}\right)$} & Main & 1.36 & 0.27 & 1.24 & 0.36 & 2.62 & 0.62 \\
\hline & $\mathrm{Sec}$ & 1.37 & 0.32 & 1.32 & 0.38 & 3.00 & 0.80 \\
\hline & Pool & 1.38 & 0.34 & 1.39 & 0.23 & 3.10 & 0.38 \\
\hline \multirow[t]{3}{*}{$\mathrm{TCO}_{2}(\mathrm{mM})$} & Main & 2.14 & 0.21 & 2.32 & 0.23 & 1.88 & 0.40 \\
\hline & $\mathrm{Sec}$ & 2.34 & 0.58 & 2.20 & 0.29 & 1.92 & 0.50 \\
\hline & Pool & 2.21 & 0.32 & 2.51 & 0.43 & 1.96 & 0.53 \\
\hline
\end{tabular}

Main, main channels; sec, secondary channels; pool, pools. 
communities. Moreover, comparing the two graphs, it can be seen that the segregation between mesohabitats resulted slightly greater during the seasonal phase (November and April) than for summer. We also found a variability of communities in time (Fig. 3C), with a clear segregation of autumn, spring and summer data in three different clusters.

The mesohabitats contribution to the taxa richness at station level resulted significantly different, either seasonally $(\mathrm{P}=0.002)$ or during the summer $(\mathrm{P}=0.045)$. The greater contribution was the one given by marginal mesohabitats and by the secondary channels in particular, while the importance of main channels resulted limited (Fig. 4).

Variation during the summer phase of the Sørensen Dissimilarity index and of the beta-diversity partition for the pairwise comparisons between mesohabitats are reported in Fig. 5 A,B. The dissimilarity values (Sørensen Dissimilarity index) showed similar trends in all comparisons, with a decrease in June and July (T1:T5 in Fig. 5A) and a new increase at the beginning of autumn (T6, T7). Nevertheless, this trend resulted significant only considering the comparison between main channels and pools $(\mathrm{P}=0.027)$. The two components of beta-diversity resulted significantly different for all the comparison $(\mathrm{P}<0.001)$, with higher values for taxa turnover. No significant temporal trends resulted from the analysis.

\section{DISCUSSION AND CONCLUSIONS}

This study highlights a strong variability of macroinvertebrate assemblages in BRs, with different mesohabitats hosting different communities. These findings are consistent with Gray and Harding (2009), Zilli and Marchese (2011), Karaus et al. (2013) and Starr et al. (2014), that reported significant levels of variation of taxa richness and abundance among mesohabitats inside river reaches. Arscott et al. (2005) found greater diversity in macroinvertebrate communities of backwaters areas of Tagliamento River, while Gray and Harding (2009) pointed out spring creeks, spring sources and ponds and Zilli and Marchese (2011) isolated lakes as mesohabitats hosting greater diversity in New Zealand rivers and in Panamá River floodplain, respectively. By contrast, in our systems secondary channels resulted as being the mesohabitat hosting greater taxa diversity, both for seasonal and summer data, while in the other works these mesohabitats resulted in those with low diversity compared to the other ones. This higher diversity could be explained considering that secondary channels were characterized by intermediate levels of hydrological disturb (mean discharge, depth and water velocity), were often located near the margin of riverbeds and presented a higher heterogeneity of microhabitats (cobbles, gravel, clay, algal mats and roots). These features have been shown to be critical
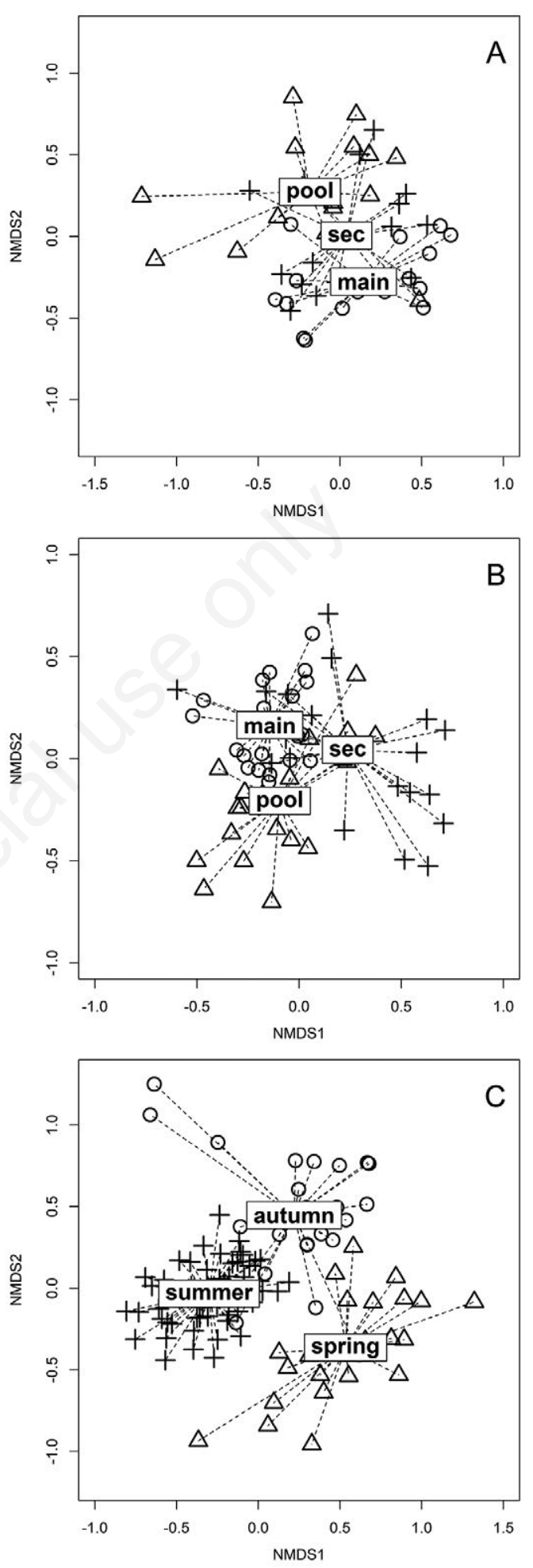

Fig. 3. nMDS ordination outputs for seasonal (A), summer (B) and all (C), data. For seasonal and summer data (A and B) the mesohabitat segregation is shown, while for the all data graph (C) the temporal (between seasons) segregation of communities is shown. Seasonal nMDS stress, 0.176; Summer nMDS stress, 0.157 ; all data nMDS stress, 0.175 ; main, main channels; sec, secondary channels; pool, pools. 
in enhancing the within site richness (Downes et al., 2000). Additionally, they show greater shadowing levels that significantly modulate the colonization patterns of primary producers (algae, vascular macrophytes; data not shown), influencing the availability of resources for macroinvertebrates.

Several factors have been proposed as main drivers for BRs macroinvertebrate community differentiation: conductivity and percentage of sand (Zilli and Marchese, 2011), flow velocity (Arscott et al., 2005), nature of substrate (Beisel et al., 1998). In our work, we considered the mesohabitat category as a proxy of physical environment differentiation: in particular, we found that main channels, secondary channels and pools mainly differed in flow velocity and water depth. Given the high significance of mesohabitats for macroinvertebrate, we hypothesized a strong physical control of communities, with a selection of taxa based on their habitat needs, also suggested by the presence of unique taxa for different mesohabitats.

A temporal trend that arose from our results is the evident difference in the importance of mesohabitats between seasonal and summer phases, supported by both mixed effects modelling and nMDS ordination. These findings are in contrast with Starr et al. (2014) and Arscott et al. (2003), who reported an increase of compositional heterogeneity coming from the increasing isolation of sampling sites, and from flood homogenization respectively. García-Roger et al. (2011) instead found similar results, with a mesohabitat (riffles and pools in their study) differentiation smaller during the dry season for a decrease of mesohabitat heterogeneity. The greater differentiation of mesohabitat communities observed in the present study during seasonal samplings (November and April) could be the result of a major connectivity that allows organisms to actively choose the best living place, according to their necessities. This generates a high environmental control on the community from the moment that there are no dispersal limitations and the choice of the most suitable environmental features drives the community. On the other hand, during summer the disconnection increases, hampering the dispersion of organisms. Unlike our initial hypothesis, in this phase we observe a temporal trend of community dissimilarity reduction between mesohabitats, coupled with a prevalence of taxa turnover on taxa loss. These phenomena could be due to a general loss of the more sensitive and specialized taxa, which leads to the homogenization of communities. Nevertheless, the turnover remains greater than nestedness, suggesting the presence of taxa well adapted to the different conditions of mesohabitats and able to manage with the effects of flow reduction.

This work provides significant insights, also into the biomonitoring procedures. Hence, for BRs the Italian legislation limits the range of application of the standard biomonitoring methods to the main channel. This choice, based on our data, could lead to collect samples unrepresentative of the real communities, with a loss of $20 \%$ of families, and to obtain incorrect evaluations. In BRs the
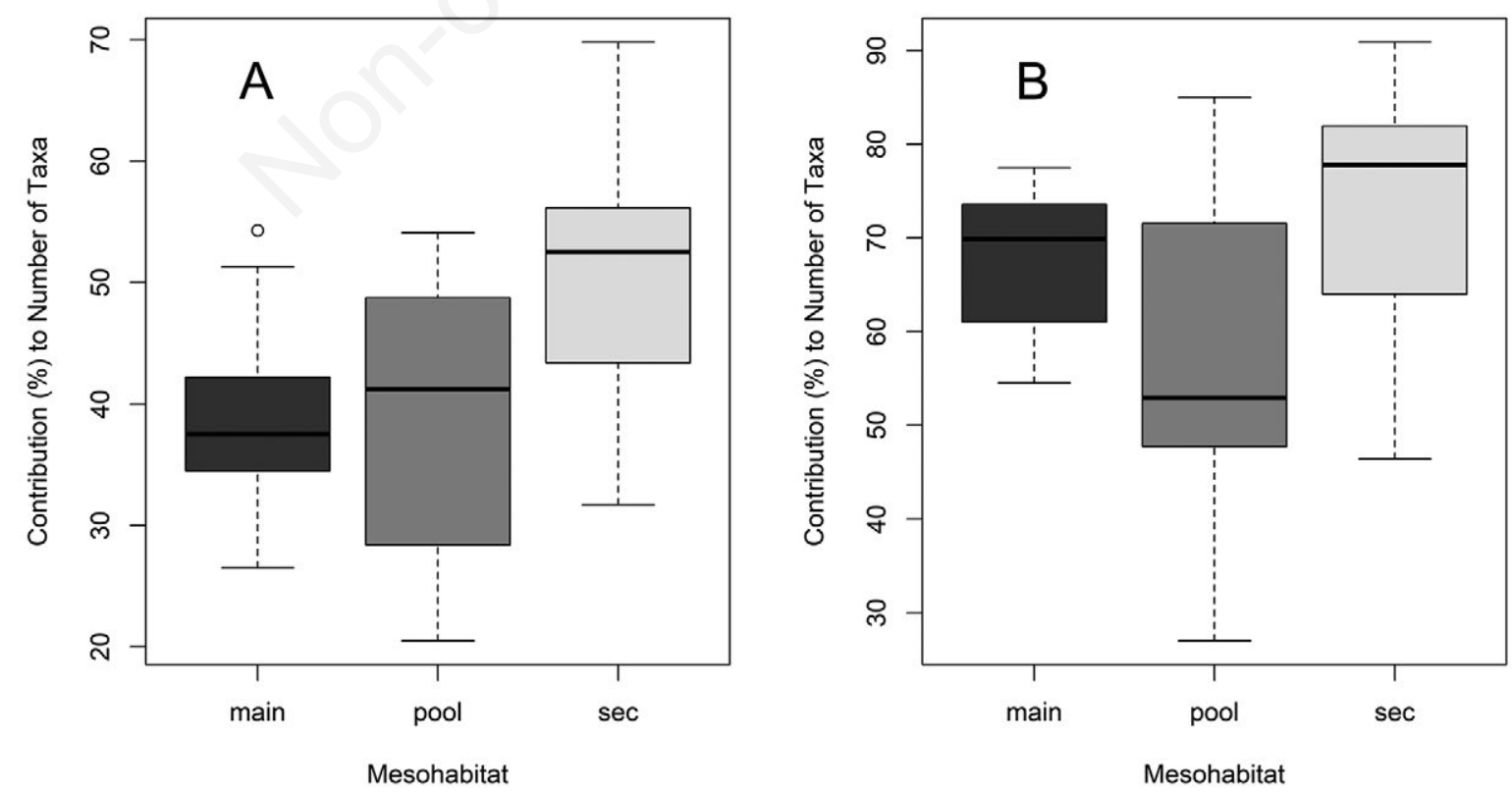

Fig. 4. Mesohabitat contribution to the total number of taxa for seasonal (A) and summer data (B). Main, main channels; sec, secondary channels; pool, pools. 
distribution of benthic macroinvertebrates exhibits high levels of heterogeneity and therefore the ecological status cannot be evaluated considering exclusively the main channels, but it should be assessed considering the river ecosystem as a whole, including marginal water bodies (secondary channels and pools) that are common in these environments.

\section{ACKNOWLEDGMENTS}

This research was partly supported by the "Consorzio di Bonifica di Piacenza" (Emilia Romagna Region) within the framework of the project "Evaluation of relationships between hydrology and ecological and functional features of Trebbia River (2015-2016)". This paper is also a
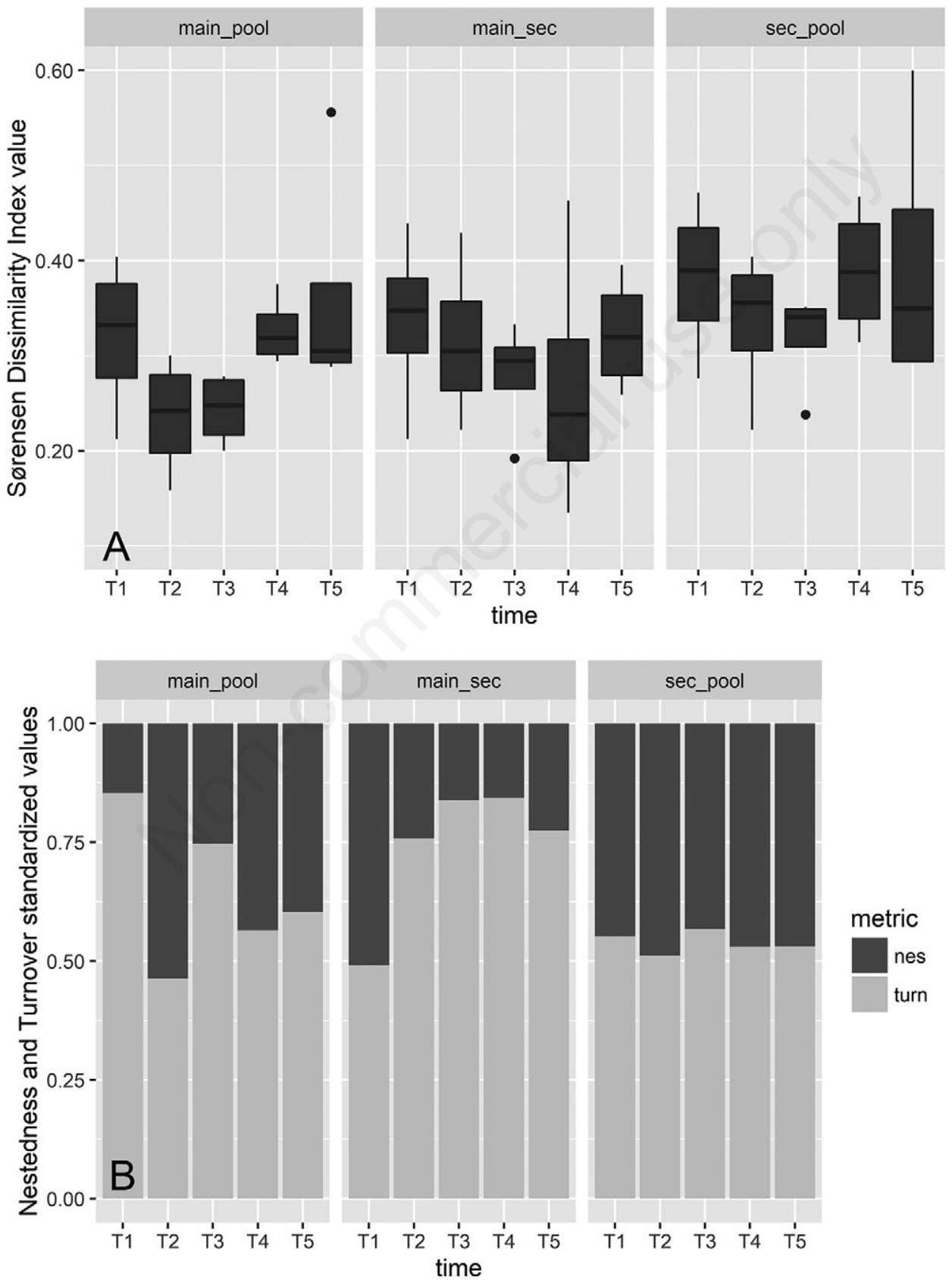

Fig. 5. Short-term variation of Sørensen dissimilarity index (A) and nestedness and turnover components (B), in the three pairwise confrontations between mesohabitats (main_pool, main channel-pool; main_sec, main channel-secondary channel: sec_pool, secondary channel-pool). Nestedness and turnover values were standardized by dividing by the Sørensen index. T1:T5, sampling campaigns. 
contribution to the Italian National Relevant Project (PRIN2015) NOACQUA-responses of communities and ecosystem processes in intermittent rivers.

We gratefully acknowledge the technical and field support provided by Dr. E. Russo and her staff (Arpae Sezione di Piacenza). Thanks also to Dr. S. Guareschi and M. Saccò for the field support and to Sandra Craighead for the English revision. A. Laini was partly funded by the University of Parma. This paper is an outcome of the research of $\mathrm{G}$. Burgazzi within the PhD program in Evolutionary Biology and Ecology $\left(30^{\text {th }}\right.$ cycle $)$ of the Universities of Parma and Ferrara.

\section{REFERENCES}

APHA-AWWA-WPCF, 2012. Standard methods for the examination of water and wastewater. 22nd ed. Am. Publ. Health. Ass., Washington: $1360 \mathrm{pp}$.

Arscott DB, Tockner K, Ward JV, 2003. Spatio-temporal patterns of benthic invertebrates along the continuum of a braided Alpine river. Arch. Hydrobiol. 158:431-460.

Arscott DB, Tockner K, Ward JV, 2005. Lateral organization of aquatic invertebrates along the corridor of a braided floodplain river. J. N. Am. Benthol. Soc. 24:934-954.

Astorga A, Death R, Death F, Paavola R, Chakraborty M, Muotka T, 2014. Habitat heterogeneity drives the geographical distribution of beta diversity: the case of New Zealand stream invertebrates. Ecol. Evol. 13:2693-2702.

Baselga A, 2010. Partitioning the turnover and nestedness components of beta diversity. Global Ecol. Biogeogr. 19:134-143.

Baselga A, Orme D, Villeger S, De Bortoli J, Leprieur F, 2013. betapart: Partitioning beta diversity into turnover and nestedness components. R package ver. 1.3. Available from: https://CRAN.R-project.org/package=betapart

Bates D, Maechler M, Bolker B, Walker S, 2015. Fitting linear mixed-effects models using lme4. J. Stat. Softw 67:1-48.

Beisel JN, Usseglio-Polatera P, Thomas S, Moreteau JC, 1998. Stream community structure in relation to spatial variation: the influence of mesohabitat characteristics. Hydrobiologia 389:73-88.

Bolpagni R, Laini A, 2016. Microhabitat patterns of soft-bodied benthic algae in a lowland river largely fed by groundwater. Fottea 16:244-254.

Borcard D, Gillet F, Legendre P, 2011. Numerical ecology with R. Springer, New York: 306 p.

Datry T, Bonada N, Heino J, 2016. Towards understanding the organisation of metacommunities in highly dynamic ecological systems. Oikos 125:149-159.

Dodds WK, 2002. Freshwater ecology: concepts and environmental applications. Academic Press, Cambridge: 569 pp.

Downes BJ, Hindell JS, Bond NR, 2000. What's in a site? Variation in lotic macroinvertebrate density and diversity in a spatially replicated experiment. Austral. Ecol. 25:128-139.

Garcia XF, Schnauder I, Pusch MT 2012. Complex hydromorphology of meanders can support benthic invertebrate diversity in rivers. Hydrobiologia 685:49-68.

García-Roger EM, del Mar Sánchez-Montoya M, Gómez R, Suárez ML, Vidal-Abarca MR, Latron J, Rieradevall M, Prat N, 2011.
Do seasonal changes in habitat features influence aquatic macroinvertebrate assemblages in perennial versus temporary Mediterranean streams? Aquat. Sci. 73:567-579.

Golterman HL, Clymo RS, Ohnstad MA, 1978. Methods for physical and chemical analysis of freshwater. 2nd ed. JNP Handbook, N. 8.

Gray DP, Harding JS, 2007. Braided river ecology: a literature review of physical habitats and aquatic invertebrate communities. Science \& Technical Publ., Department of Conservation.

Gray D, Harding JS, 2009. Braided river benthic diversity at multiple spatial scales: a hierarchical analysis of $\beta$ diversity in complex floodplain systems. J. N. Am. Benthol. Soc. 28:537-551.

Gray DP, Harding JS, 2011. Multi-scaled environmental determinism of benthic invertebrate communities in braided rivers: evidence for complex hierarchical controls on local communities. Fundam. Appl. Limnol./Arch. Hydrobiol. 179:3-15.

Karaus U, Larsen S, Guillong H, Tockner K, 2013. The contribution of lateral aquatic habitats to insect diversity along river corridors in the Alps. Landscape Ecol. 28:1755-1767.

Leibold MA, Holyoak M, Mouquet N, Amarasekare P, Chase JM, Hoopes MF, Holt RD, Shurin JB, Law R, Tilman D, Loreau M, Gonzalez A, 2004. The metacommunity concept: a framework for multi-scale community ecology. Ecol. Lett. 7:601-613.

McCulloch CE, Neuhaus JM, 2005. Generalized Linear Mixed Models. Encyclopedia of Biostatistics. 4.

McLaughlin OB, Emmerson MC, O’Gorman EJ, 2013. Chapter Four-Habitat Isolation Reduces the Temporal Stability of Island Ecosystems in the Face of Flood Disturbance. Adv. Ecol. Res. 48:225-284.

Oksanen J, Blanchet FG, Kindt R, Legendre P, Minchin PR, O'Hara RB, Simpson GL, Solymos P, Stevens MHH, Wagner H, 2016. vegan: Community Ecology Package. R package ver. 2.3-5. Available from: https://CRAN.R-project.org/package $=$ vegan

Padial AA, Ceschin F, Declerck SA, De Meester L, Bonecker CC, Lansac-Tôha FA, Rodrigues L, Rodrigues LC, Train S, Velho LFM, Bini LM, 2014. Dispersal ability determines the role of environmental, spatial and temporal drivers of metacommunity structure. PLoS One 9:e111227.

Poff NL, Ward JV. 1990. Physical habitat template of lotic systems: recovery in the context of historical pattern of spatiotemporal heterogeneity. Environ. Manage. 14:629-645.

R Core Team, 2016. R: A language and environment for statistical computing. R Foundation for Statistical Computing, Vienna, Austria. Available from: https:/www.R-project.org/

Siqueira T, Bini LM, Roque FO, Cottenie K, 2012. A metacommunity framework for enhancing the effectiveness of biological monitoring strategies. PLoS One 7:e43626.

Starr SM, Benstead JP, Sponseller RA, 2014. Spatial and temporal organization of macroinvertebrate assemblages in a lowland floodplain ecosystem. Landscape Ecol. 29:1017-1031.

Tachet H, Richoux P, Bournaud M, Usseglio-Polatera P, 2010. [Invertébrés d'eau douce: systématique, biologie, écologie].[Book in French]. CNRS Ed, Paris: 588 pp.

Tickner D, Armitage PD, Bickerton MA, Hall KA, 2000. Assessing stream quality using information on mesohabitat dis- 
tribution and character. Aquat. Conserv. 10:179-196. Tockner K, Paetzold A, Karaus U, Claret C, Zettel J, 2006. Ecology of braided rivers, p. 339359. In: G.H. Sambrook Smith, J.L. Best, C.S. Bristow and G.E. Petts (eds.), Braided rivers: Process, deposits, ecology and management. Blackwell Publishing Ltd., Oxford.

Valderrama JC, 1977. Methods used by the Hydrographic Department of National Board of Fisheries, Sweden, p. 13-40. In: Report of the Baltic Intercalibration Workshop. Annex, Interim Commission for the Protection of the Environment of the Baltic Sea.
Van Der Nat D, Tockner K, Edwards PJ, Ward JV, Gurnell AM, 2003. Habitat change in braided flood plains (Tagliamento, NE-Italy). Freshwater Biol. 48:1799-1812.

Ward JV, Tockner K, Arscott DB, Claret C, 2002. Riverine landscape diversity. Freshwater Biol. 47:517-539.

Wickham H, 2009. ggplot2: elegant graphics for data analysis. Springer, New York: 212 pp.

Zilli FL, Marchese MR, 2011. Patterns in macroinvertebrate assemblages at different spatial scales. Implications of hydrological connectivity in a large floodplain river. Hydrobiologia 663:245-257. 